\title{
Hospital ward design and prevention of hospital-acquired infections: A prospective clinical trial
}

\author{
Jennifer Ellison $\mathrm{MSc}^{1}$, Danielle Southern $\mathrm{MSc}^{2,3}$, Donna Holton $\mathrm{MD}^{1,4}$, Elizabeth Henderson $\mathrm{PhD}^{1,2}$, \\ Jean Wallace $\mathrm{PhD}^{5}$, Peter Faris $\mathrm{PhD}^{2,3}$, William A Ghali $\mathrm{MD}^{1,2,3,4}$, John Conly $\mathrm{MD}^{1,3,4,6}$
}

\begin{abstract}
J Ellison, D Southern, D Holton, et al. Hospital ward design and prevention of hospital-acquired infections: A prospective clinical trial. Can J Infect Dis Med Microbiol 2014;25(5):265-270.
\end{abstract}

BACKGROUND: Renovation of a general medical ward provided an opportunity to study health care facility design as a factor for preventing hospital-acquired infections.

OBJECTIVE: To determine whether a hospital ward designed with predominantly single rooms was associated with lower event rates of hospital-acquired infection and colonization.

METHODS: A prospective controlled trial with patient allocation incorporating randomness was designed with outcomes on multiple 'historic design' wards (mainly four-bed rooms with shared bathrooms) compared with outcomes on a newly renovated 'new design' ward (predominantly single rooms with private bathrooms).

RESULTS: Using Poisson regression analysis and adjusting for time at risk, there were no differences $(\mathrm{P}=0.18)$ in the primary outcome (2.96 versus 1.85 events/1000 patient-days, respectively). After adjustment for age, sex, Charlson score, admitted from care facility, previous hospitalization within six months, isolation requirement and the duration on antibiotics, the incidence rate ratio was 1.44 (95\% CI 0.71 to 2.94) for the new design versus the historic design wards. A restricted analysis on the numbers of events occurring in single-bed versus multibed wings within the new design ward revealed an event incidence density of 1.89 versus 3.47 events/1000 patient-days, respectively $(\mathrm{P}=0.18)$, and an incidence rate ratio of 0.54 (95\% CI 0.15 to 1.30$)$. CONCLUSIONS: No difference in the incidence density of hospitalacquired infections or colonizations was observed for medical patients admitted to a new design ward versus historic design wards. A restricted analysis of events occurring in single-bed versus multibed wings suggests that ward design warrants further study.

Key Words: Antibiotic-resistant organism; Controlled trial; Hospitalacquired infection; Incidence density; Multibed room; Physical plant; Single room; Ward design

$\mathrm{T}$ he importance of health care facility design as a basic component of preventing infectious disease transmission has been discussed for many years (1). Recent studies have underscored the importance of optimizing design standards to maximize patient and health care worker safety (2-6) including the prevention of health care-acquired infections, with an estimated direct cost in the United States of between $\$ 35.7$ and $\$ 45$ billion annually (7). Ulrich et al (8) identified $>600$ studies that examined the hospital environment and its effects on staff effectiveness, patient safety, patient and family stress, quality and costs. They suggested that an important element in improving patient safety was

\section{La conception des unités d'hospitalisation et la prévention des infections nosocomiales : un essai clinique prospectif}

HISTORIQUE : La rénovation d'une unité d'hospitalisation générale a permis d'étudier la conception des établissements de santé comme facteur pour prévenir les infections nosocomiales.

OBJECTIF : Déterminer si une unité d'hospitalisation contenant surtout des chambres individuelles s'associe à un taux plus faible d'infections nosocomiales et de colonisations.

MÉTHODOLOGIE : Un essai prospectif contrôlé avec répartition aléatoire des patients a permis de comparer les résultats dans diverses " anciennes » unités (surtout des chambres à quatre lits dont les toilettes sont partagées) à ceux dans des unités « rénovées » (surtout des chambres individuelles dotées de toilettes individuelles).

RÉSULTATS : D'après l'analyse de régression de Poisson et après rajustement en fonction du temps à risque, il n'y avait pas de différences $(\mathrm{P}=0,18)$ dans les résultats primaires $(2,96$ par rapport à 1,85 événements sur 1000 patients-jour, respectivement). Après rajustement compte tenu de l'âge, du sexe, de l'indice de Charlson, de l'admission en provenance d'un établissement de soins, d'une hospitalisation dans les six mois précédents, de la nécessité d'isolement et de la durée de l'antibiothérapie, le ratio d'incidence était de 1,44 (95 \% IC 0,71 à 2,94) pour les nouvelles chambres par rapport aux anciennes. Une analyse restreinte du nombre d'événements qui se produisent dans les nouvelles unités de chambres individuelles plutôt que de chambres communes a révélé une densité d'incidence de 1,89 par rapport à 3,47 événements sur 1000 patients-jour, respectivement $(\mathrm{P}=0,18)$, et un ratio d'incidence de 0,54 (95\% IC 0,15 à 1,30).

CONCLUSIONS : Il n'y avait pas de différence dans la densité d'incidence des infections nosocomiales ou des colonisations chez les patients admis dans une nouvelle unité plutôt qu'une ancienne. D'après une analyse restreinte des événements qui se produisent dans des unités de chambres individuelles plutôt que de chambres communes, la conception des unités devrait faire l'objet d'études plus approfondies.

reducing hospital-acquired infections. Several factors unique to the hospital environment may contribute to an increased propensity for hospital-acquired infections and transmission of antimicrobial-resistant pathogens, including physical plant design, engineering controls (sink placement, space design to facilitate hygienic practices, ease of handwashing, ability to maintain general environmental hygiene), the use of aseptic technique and the host-health care provider interaction (8). These environmental factors have taken on increasing importance in recent years, especially with the increased acuity in the types of patients admitted to health care facilities. To date, studies examining

${ }^{1}$ Alberta Health Services, Calgary and Area; ${ }^{2}$ Department of Community Health Sciences; ${ }^{3}$ Institute for Public Health; ${ }^{4}$ Department of Medicine,

Faculty of Medicine; ${ }^{5}$ Department of Sociology, Faculty of Arts; ${ }^{6}$ Calvin, Phoebe and Joan Synder Institute for Chronic Diseases, Faculty of

Medicine, University of Calgary, Alberta Health Services, Calgary and Area, Calgary, Alberta

Correspondence: Dr John Conly, AGW5, Foothills Medical Centre, 1403-29th Street Northwest, Calgary, Alberta T2N 2 T9.

E-mail jconly@ucalgary.ca 
environmental factors have been of quasiexperimental design using before-after interventions. With the construction of a new medical teaching ward with features designed to reduce hospital-acquired infections, an opportunity existed to rigorously study the impact of hospital ward design on specific hospital-acquired infections and antibioticresistant organism (ARO) colonization. In the first four years of operation, the incidence density of hospital-acquired infections and/or colonization with AROs, including methicillin-resistant Staphylococcus aureus (MRSA), vancomycin-resistant enterococci (VRE) and Clostridium difficile, declined by almost 70\% (9). Given that there were no changes in the types of patients, medical, nursing or housekeeping staff, we hypothesized that the design of the new ward was the major factor that contributed to the improved outcomes and designed a prospective, controlled study to examine this hypothesis.

\section{METHODS}

\section{Study design and allocation procedure}

The study design was a prospective, nonrandomized, controlled trial with a patient allocation plan incorporating randomness with investigatorblinded ascertainment of outcomes. General medical patients were allocated to one of two types of medical wards at a tertiary health care facility, either the intervention ('new design') ward, which had been extensively renovated, or the control ('historic design') wards, constructed $>40$ years previously. Because random allocation would not be possible in the setting of high bed occupancy and the need to maintain expedient patient flow through the emergency room, a 2:1 patient allocation plan that incorporated randomness was developed $(10,11)$, using a two-tiered patient allocation process such that when both the new design and the historic design wards had open beds, patients were randomly assigned using a computer-generated randomization sequence with allocation concealment (achieved by maintaining the sequence and allocation assignment envelopes in Admitting) and when only either of the new design or historic design wards were available, the patient was 'assigned' to the intervention or control group, respectively. The latter scenario approximated a randomization setting because beds became available in what appeared to be a random manner.

\section{Interventions}

The historic design wards $(n=5)$ had predominantly $(>80 \%)$ four-bed rooms with shared bathrooms, less space and one handwashing sink designated for staff handwashing only in each four-bed room and no hallway handwashing sinks. The new design ward $(n=1)$ had predominantly (>80\%) single-bed rooms with private bathrooms, greater space, one handwashing sink in each room and a hallway handwashing sink between each of the rooms, both of which were designated for staff handwashing only. Alcohol-based hand rub was available at the entry to each of the rooms for both types of wards. The medical wards were otherwise very similar with respect to the patients, acuity of care, medical staff, nursing staff and skills, educational levels, housekeeping and levels of knowledge about infection control practices. Controlling for these other variables, which may otherwise have confounded the outcome, enabled the effect of the differences in design, construction and engineering controls to be studied.

\section{Enrollment}

From June 2007 to February 2010, all patients admitted to the general internal medicine service at the authors' facility from the emergency room, urgent assessment clinic or the community were assessed for eligibility for the present study. Patients were excluded if they were admitted from another health care facility (acute or long-term care), another hospital ward, transferred from the intensive care unit (ICU), required telemetry, were $<18$ years of age, were admitted to a nonstudy unit, or were preferentially admitted to the new or historic design ward based on clinical grounds according to the attending physician.

\section{Data collection procedures}

Patients who were admitted to either the new or historic design ward(s) and remained there for $>48 \mathrm{~h}$ were monitored for the development of the primary outcome of a hospital-acquired infection or colonization event due to MRSA, VRE or C difficile while remaining on the ward. The definitions for these events (occurring $>72 \mathrm{~h}$ after admission) were based on the definitions used by the Public Health Agency of Canada (12). The process of identifying the hospital-acquired events included an active review of a computerbased clinical information system followed by a linkage to the facility's infection prevention and control database to identify any cases that may have developed after the patients were discharged from the study. Sample size determination was based on the estimated number of events and days of observation for each of the ward designs and, assuming that incident cases followed a Poisson distribution, it was determined that 43 events were required to detect a $60 \%$ difference in incidence densities with a power of $80 \%$ and an alpha level of 0.05 . In an effort to identify additional outcomes, one year into the study, a protocol amendment was introduced to undertake active surveillance for MRSA. Following approval by the Conjoint Research Ethics Board, patients who were admitted into the study were asked to sign a consent form permitting a swab of the nares, axillae and groins for MRSA. MRSA was identified using standard laboratory procedures.

Data were collected on multiple variables: patient demographics (age, sex, date of admission); hospitalization (previous hospitalizations, setting of current admission and number of room changes, length of stay); illness (comorbidities, Charlson Comorbidity Index and International Classification of Diseases, 10th Revision codes from administrative databases); antimicrobial usage (during hospital stay) from the pharmacy's computer system (Centricity, GE Healthcare, United Kingdom); daily census of patients and workload to staffing ratio from the facility's administrative databases; and room cleaning from the housekeeping database (BedTracking Version 3.06.0500, TeleTracking Technologies Inc, USA). The Infection Prevention and Control Unit provided information about educational sessions on the wards.

\section{Analysis}

Baseline clinical, demographic and hospital stay characteristics of patients with and without an event for one of the three organisms were compared using a $\chi^{2}$ test for categorical variables and Student's $t$ test for continuous variables. For the primary outcome analysis, incidence density was calculated for those with and without an event. Poisson regression analysis was used to calculate incidence rate ratios (IRRs) with $95 \%$ Cls for a positive event, adjusting for length of time an individual was at risk. The Poisson regression analyses were adjusted for age, sex and Charlson Comorbidity Index score as well as for admission from a care facility and previous hospitalization within six months. A secondary analysis included the number of outbreaks of ARO events on the wards. All analyses were conducted using SAS version 9.2 (SAS Institute, USA). The study protocol was registered at clinicaltrials.gov (NCT00563186).

\section{Eligibility and allocation}

\section{RESULTS}

Of 3617 patients assessed for eligibility (Figure 1), 1754 did not meet inclusion criteria, 175 were admitted more than once and one had a 'spoiled' randomization, leaving 1687 patients entering the allocation scheme of either being randomly assigned or assigned to one of the two ward designs. Only 10 patients were randomly assigned during the course of the study due to continuous overcapacity difficulties, which limited bed availability. Due to a stay $<48$ h, 97 and 74 patients allocated to the new design and historic design wards, respectively, were excluded from outcome ascertainment. There were two patients with incomplete data; therefore, 1514 patients were available for analysis, including 910 allocated to the new design ward and 604 allocated to the historic design wards.

\section{Demographic characteristics}

Patient and hospital stay characteristics are presented in Tables 1 and 2. Patients admitted to the new design ward were younger, more likely to be 
transferred elsewhere within $24 \mathrm{~h}$ of admission, had less congestive heart failure, more diabetes without chronic complications, less diabetes with chronic complications, less often had a diagnosis of hemiplegia/paraplegia and metastatic solid tumour, and had significantly fewer comorbidities, as measured by the mean Charlson Comorbidity Index score (Table 1). Patients allocated to the new design ward were also significantly more likely to be discharged home, require isolation, stay in a single-bed room and have a longer duration of antibiotic treatment (Table 2). The mean discharge cleaning time for the new versus historic design wards did not differ significantly among the daytime, evening and night shifts during the course of the study. Similarly, the measurements of nursing workload indexes demonstrated no major differences between the new design versus historic design wards. The coverage by members of the Infection Prevention and Control Unit for the hospital, the number and types of in-service education provided and the patterns of surveillance were similar for both types of wards during the course of the study.

Incidence density of hospital-acquired infections/colonizations The results of the primary outcomes for the study are presented in Table 3. There were no significant differences in the primary outcome of the overall incidence density of hospital-acquired infections/colonizations between the new design ward and the historic design wards. Patients admitted to the new design ward versus the historic design wards had a higher number of incident cases of

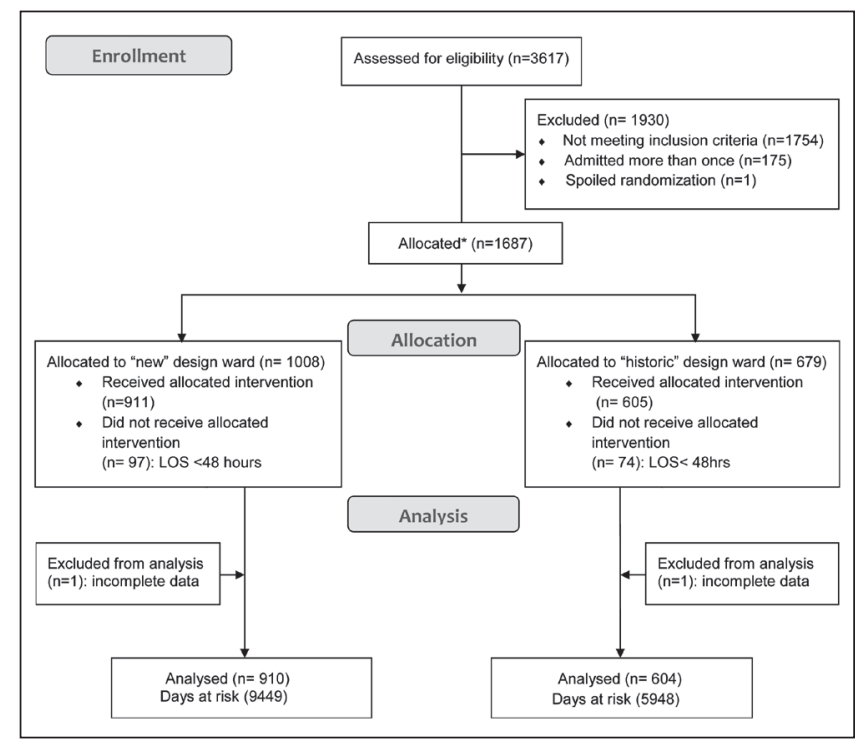

Figure 1) CONSORT flow diagram.*Refer to Methods section for details of allocation scheme. LOS Length of stay

TABLE 1

Patient characteristics

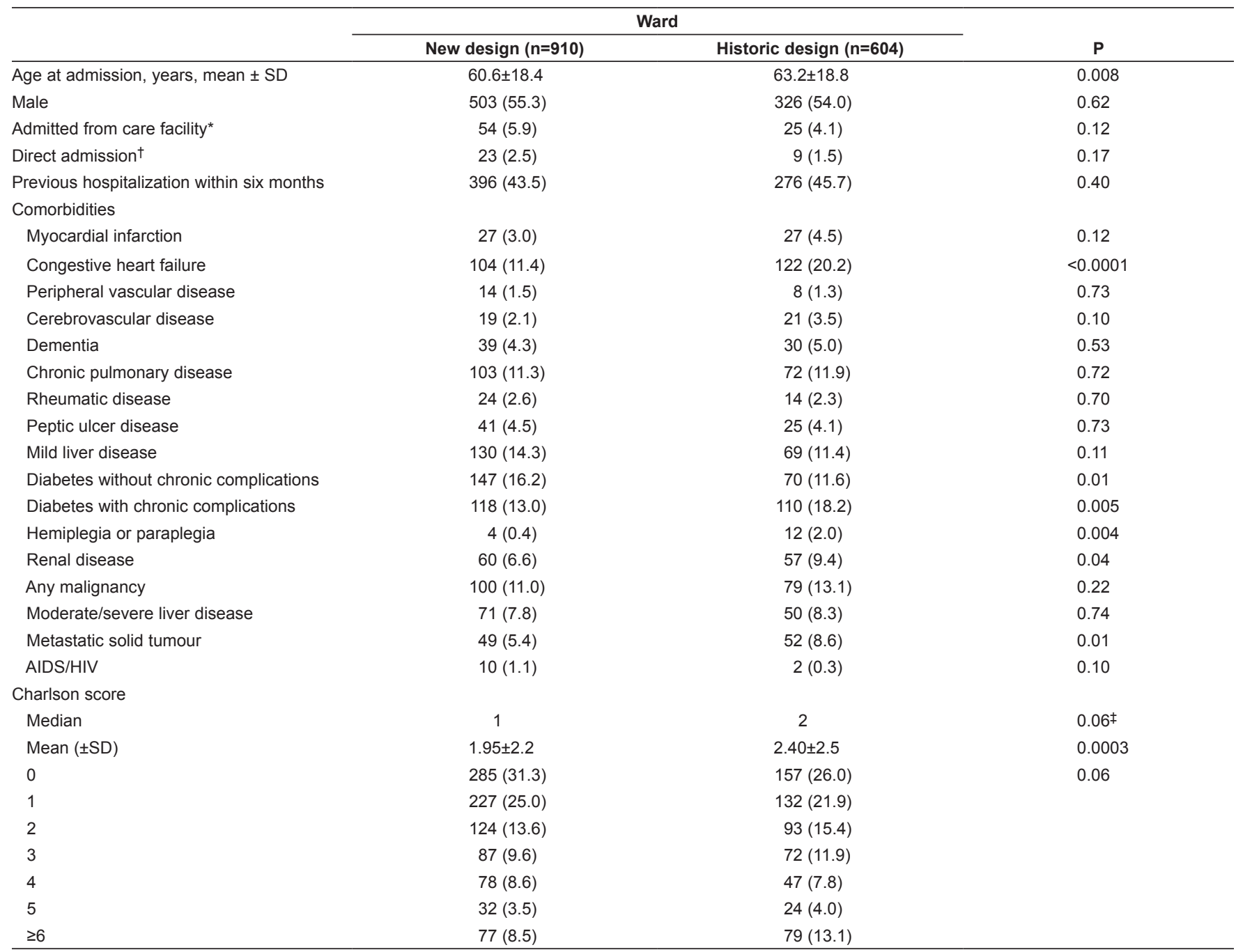

Data presented as $n(\%)$ unless otherwise indicated. *Care facilities include rehabilitation or long-term care; ${ }^{\dagger}$ Direct admission without emergency room; ${ }^{\ddagger} P$ value calculated using F-test 
TABLE 2

Characteristics of the hospital stay

\begin{tabular}{|c|c|c|c|}
\hline \multirow[b]{2}{*}{ Characteristic } & \multicolumn{2}{|c|}{ Ward } & \multirow[b]{2}{*}{$\mathbf{P}$} \\
\hline & New design $(n=910)$ & Historic design $(n=604)$ & \\
\hline Length of stay in hospital, days, mean \pm SD & $10.8 \pm 16.4$ & $9.9 \pm 13.6$ & $0.28^{*}$ \\
\hline Time at risk for $A R O$, days, mean $\pm S D$ & $10.4 \pm 14.5$ & $9.8 \pm 13.5$ & $0.47^{*}$ \\
\hline Transferred from study unit to ICU or other unit & $114(12.5)$ & $117(19.4)$ & 0.002 \\
\hline Isolation was required for other reasons & $125(13.7)$ & $36(6.0)$ & $<0.0001$ \\
\hline Multibed room at some point & $436(47.9)$ & $538(89.1)$ & $<0.0001$ \\
\hline Days on antibiotics, mean \pm SD & $5.7(7.9)$ & $4.9(6.6)$ & 0.03 \\
\hline Disposition & & & 0.05 \\
\hline Died & $72(7.9)$ & $50(8.3)$ & \\
\hline Discharge home with services & $76(8.4)$ & $79(13.1)$ & \\
\hline Discharge home & $625(68.7)$ & $380(62.9)$ & \\
\hline Signed out against medical advice & $21(2.3)$ & $8(1.3)$ & \\
\hline
\end{tabular}

Data presented as $n(\%)$ unless otherwise indicated. ARO Antibiotic-resisitant organisms; GIM General internal medicine; ICU Intensive care unit

TABLE 3

Hospital-acquired infections and colonization events

\begin{tabular}{|c|c|c|c|}
\hline \multirow[b]{2}{*}{ Outcomes } & \multicolumn{2}{|c|}{ Ward } & \multirow[b]{2}{*}{$\mathbf{P}$} \\
\hline & $\begin{array}{l}\text { New design } \\
\quad(n=910)\end{array}$ & $\begin{array}{l}\text { Historic design } \\
\qquad(n=604)\end{array}$ & \\
\hline \multicolumn{4}{|l|}{ Positive events } \\
\hline Number of cases & 28 & 11 & \\
\hline Days at risk & 9449 & 5948 & \\
\hline $\begin{array}{l}\text { Incidence density (per } \\
1000 \text { patient-days at risk) }\end{array}$ & 2.96 & 1.85 & 0.18 \\
\hline \multicolumn{4}{|l|}{ Type of event } \\
\hline CDI & 11 & 5 & \\
\hline MRSA & 12 & 6 & \\
\hline VRE & 5 & 0 & \\
\hline \multirow{2}{*}{\multicolumn{4}{|c|}{$\begin{array}{l}\text { Incidence density (per } \\
1000 \text { patient-days at risk) }\end{array}$}} \\
\hline & & & \\
\hline CDI & 1.16 & 0.84 & 0.57 \\
\hline MRSA & 1.27 & 1.01 & 0.67 \\
\hline VRE & 0.53 & 0 & 0.09 \\
\hline
\end{tabular}

CDI Clostridium difficile infection; MRSA Methicillin-resistant Staphylococcus aureus; VRE Vancomycin-resistant enterococcus

hospital-acquired infections or colonization events (3.1\% versus $1.8 \%$, respectively) but the results were not significantly different $(\mathrm{P}=0.18)$ whether the events were analyzed together or for each category separately (Table 3). There were no differences in the percentage of events that were determined based on clinical grounds versus those identified by active swabbing of patients. Of the 39 events, 21 were detected clinically (16 C difficile and five MRSA) and 18 were detected on discharge screening (10 MRSA) or from secondary screening (five VRE and three MRSA) according to the a priori protocol.

\section{Adjusted incidence rate ratios}

Results from the Poisson regression analysis are presented in Tables 4 and 5. The crude IRR for the new design versus the historic design wards was 1.60 (95\% CI 0.80 to 3.22 ) for patients admitted to the new design ward compared with patients admitted to the historic design wards. After adjustment for age, sex and Charlson Comorbidity Index score, the IRR was unchanged at 1.61 (95\% CI 0.80 to 3.25$)$ but decreased to 1.52 (95\% CI 0.75 to 3.08) after adjustment for age, sex, Charlson Comorbidity Index score, admitted from care facility and previous hospitalization within six months, and to 1.44 (95\% CI
0.71 to 2.94) after adjustment for age, sex, Charlson Comorbidity Index score, admitted from care facility, previous hospitalization within six months, isolation requirement and the duration on antibiotics.

\section{Secondary analyses}

The secondary outcome of the number of outbreaks related to the primary events included two small clusters on the new design ward (one each of MRSA and VRE) and an MRSA cluster on one of the historic design wards. Of the 22 cases identified in the secondary clusters, 19 (86\%) occurred in multibed rooms, with eight and three secondary MRSA and VRE cases, respectively, in multibed rooms on the new design ward and eight secondary MRSA cases in multibed rooms on a historic design ward.

A secondary restricted analysis on the numbers of events occurring in single-bed versus multibed 'wings' within a ward, as opposed to wards, was performed to examine the events occurring where only single-bed rooms existed, which was closest to our original study design, without the inclusion of multibed rooms. Assessing the analysis by wings within all wards, both new design and historic design, and only within the new design ward revealed event incidence densities of 1.89 versus $2.68(95 \%$ CI 0.60 to $3.70 ; \mathrm{P}=0.4)$ and 1.89 versus $3.47 / 1000$ patient-days $(95 \% \mathrm{CI}$ 0.76 to $4.90 ; \mathrm{P}=0.18)$ and crude IRRs of $0.70(95 \% \mathrm{CI} 0.23$ to 1.61$)$ and 0.54 (95\% CI 0.15 to 1.30 ), respectively.

\section{DISCUSSION}

We conducted a prospective controlled trial with a patient allocation plan incorporating randomness to assess the outcomes of key markers of hospital-acquired infections/colonizations in patients admitted to a newly designed ward with predominantly single rooms versus historic wards with predominantly multibed rooms. We attempted to control for other variables that may otherwise have confounded the outcomes. Our findings revealed no difference in the incidence density of events for the primary outcome and was not consistent with our original hypothesis. We were unable to find any major differences in nursing workload or housekeeping discharge cleaning parameters that may explain the difference. However, our secondary analysis on the numbers of events occurring in single-bed versus multibed 'wings', whether comparing all wards or as a component within the new design ward, revealed that hospital-acquired infections/ colonization events occurred 1.4 and almost two times as frequently, respectively, in the setting of multibed wings; although the result is not significant, it suggests a trend favouring single rooms.

To our knowledge, our study was the first prospective controlled trial that addressed this important topic. A systematic review examining the evidence for the effects of interventions to improve hospital 
TABLE 4

Adjusted Poisson regression analysis

\begin{tabular}{lc}
\hline Risk adjustments & $\begin{array}{c}\text { Incidence rate ratio* } \\
\text { (CI) }\end{array}$ \\
\hline Crude & $1.60(0.80-3.22)$ \\
Age, sex and Charlson score & $1.61(0.80-3.25)$ \\
$\begin{array}{l}\text { Age, sex, Charlson score, admitted from care facility } \\
\text { and previous hospitalization within } 6 \text { months }\end{array}$ & $1.52(0.75-3.08)$ \\
$\begin{array}{l}\text { Age, sex, Charlson score, admitted from care facility, } \\
\text { previous hospitalization within } 6 \text { months, isolation } \\
\text { required and days on antiobiotics }\end{array}$ & $1.44(0.71-2.94)$ \\
\hline
\end{tabular}

${ }^{*}$ Reference group = historic design ward. Rate ratio calculated using Poisson regression with adjustment for length of time an individual was at risk; ${ }^{\dagger}$ Additional variables determined from univariate analysis - see Table 5

design on the occurrence of hospital-acquired infections identified no randomized controlled studies (13). The majority of the 178 studies identified were expert opinion and consensus statements (13). Similarly, a recent literature review on this topic found no randomized controlled trials and only three quasiexperimental studies, all of low quality (14). Two recent prospective before-after cohort studies in hospital ICUs that had multibed rooms converted to private rooms found a $54 \%$ decrease of acquisition in combined cases of MRSA, VRE and $\mathrm{C}$ difficile (15) and a $72 \%$ decrease in the risk of acquiring any drug-resistant bacteria (16), respectively. However, an interventional interrupted time-series cohort study that studied the transmission of MRSA in an ICU (17) showed no benefit from the use of isolation rooms, although this study was less rigorously designed.

Our study extends the existing literature in this area through its use of a stronger study design. Unfortunately, our study had several confounding variables, many of which were beyond our control.

We believe the new ward design intervention was compromised in its potential to prevent hospital-acquired infections. A major factor that may have influenced the risk for a hospital-acquired event occurring on the new design ward was the significant reduction of the ward's ability to function as a predominantly single-bed ward. Due to capacity issues, the regional administration converted three of the single rooms on the ward to multibed rooms shortly after our study began; thus, the ability of the ward to function as a predominantly single-bed ward was significantly compromised. Two of the three distinct wings that radiate out from the central nursing station functioned as multibed units following this administrative decision. Beds in these converted rooms were in close proximity $(1 \mathrm{~m})$, which placed patients at a significant risk for hospitalacquired infections (16). Almost $50 \%$ of the patients on the new design ward experienced a stay in a multibed room following the introduction of the administrative changes. Less than $20 \%$ of the patients were anticipated to stay in a multibed room on the new design ward according to the original study design. The secondary outcomes of the clusters of hospital-acquired infections or events occurring almost exclusively in multibed rooms and the finding of a definite trend toward a higher incidence density of events when the results were analyzed using a singlebed versus multibed wing rather than ward as the focus of analysis suggests that patients within multibed settings may be at higher risk for hospital-acquired infection or colonization events.

Another factor that may have influenced the occurrence of hospital-acquired infections on the new design ward was the use of the ward as an 'isolation' centre for the hospital, given that it had the largest number of single-room beds within the hospital. In the univariate and adjusted analysis, the requirement for isolation was a significant risk factor for the occurrence of a hospital-acquired event. Thus, a greater burden of patients with infections for which isolation was required were admitted to the new design ward, increasing the potential for exposure and transmission.

Despite the strength of our study design, with prospective allocation of patients, we acknowledge our study has several limitations
TABLE 5

Poisson regression analysis

\begin{tabular}{lc}
\hline Univariate variables & Rate ratio* $^{*}$ \\
\hline Age & $1.01(0.99-1.03)$ \\
Male sex & $1.14(0.60-2.13)$ \\
Admitted from care facility ${ }^{\dagger}$ & $3.45(1.52-7.83)$ \\
Direct admission ${ }^{\ddagger}$ & $1.21(0.17-8.78)$ \\
Previous hospitalization within six months & $0.95(0.51-1.79)$ \\
Comorbidities & \\
Myocardial infarction & $0.58(0.08-4.19)$ \\
Congestive heart failure & $0.75(0.32-1.80)$ \\
Peripheral vascular disease & $1.19(0.16-8.64)$ \\
Cerebrovascular disease & - \\
Dementia & $1.20(0.43-3.38)$ \\
Chronic pulmonary disease & $0.69(0.24-1.93)$ \\
Rheumatic disease & $1.77(0.54-5.75)$ \\
Peptic ulcer disease & $1.99(0.61-6.45)$ \\
Mild liver disease & $1.08(0.42-2.37)$ \\
Diabetes without chronic complications & $1.47(0.68-3.20)$ \\
Diabetes with chronic complications & $0.99(0.42-2.37)$ \\
Hemiplegia or paraplegia & - \\
Renal disease & $0.55(0.13-2.28)$ \\
Any malignancy & $0.44(0.13-1.42)$ \\
Moderate/severe liver disease & $1.50(0.53-4.22)$ \\
Metastatic solid tumour & $0.55(0.13-2.29)$ \\
AIDS/HIV & - \\
Change of attending service from GIM to other & $1.55(0.82-2.92)$ \\
Isolation was required for other reasons & $2.17(1.00-4.73)$ \\
Over complement bed & $0.61(0.24-1.56)$ \\
Days on antibiotics & $1.02(1.00-1.04)$ \\
Room change & $0.89(0.70-1.13)$ \\
\hline
\end{tabular}

${ }^{*}$ Rate ratio calculated using Poisson regression with adjustment for length of time an individual was at risk; ${ }^{\dagger}$ Care facilities include rehabilitation or long-term care; $¥$ Direct admission without emergency room. GIM General internal medicine

and confounders. We only studied three hospital-acquired pathogens and, thus, did not attempt to detect other relevant hospital-acquired organisms. In addition, we introduced an active process to identify individuals colonized with MRSA after the study began and, thus, may have missed some previous colonization events. There was no active screening for VRE and it is possible that the five cases of VRE attributable to the new design unit were acquired elsewhere, although we consider this to be less likely given the attribution after $72 \mathrm{~h}$ and the majority of cases occurred after two weeks. Furthermore, it is uncertain whether our findings are generalizable beyond a population of general medical patients. Our study was likely compromised by the ability of the ward to function as a predominantly single-bed ward with the unanticipated conversion of single rooms to multibed rooms due to capacity stresses. In addition, due to chronic overcapacity issues throughout the course of the study, we were able to truly randomly assign only a small number of patients, and required a greater allocation of patients based on bed availability rather than true random allocation. Although we believe this process was nearrandom, it may have introduced a selection bias for more severely ill patients on the new design ward.

We believe the results of the study are, nonetheless, highly relevant for policy makers, hospital planners, industrial engineers, architects, medical and nursing personnel, and governmental organizations. Although the primary outcome analysis revealed no differences, when we consider the compromised state of the new design ward's ability to function as originally planned, the adjusted Poisson regression analysis and the secondary analyses collectively suggest that there may be a true difference in hospital-acquired infection rates arising from room design. 


\section{SUMMARY}

We are not in a position to recommend whether hospital wards should or should not be configured to be predominantly single-bed rooms to prevent hospital-acquired infections on the basis of the present study. However, a lesson learned is that research of this type in a functioning health care system is inherently difficult and health system stressors would always take precedence over study design issues. Nonetheless, we have demonstrated that it is possible to perform controlled trials to study the effects of hospital ward design on the outcome of hospital-acquired infection and colonization. We have also provided a framework with which to undertake further studies and would encourage other investigators to design methodologically rigorous trials in an effort to produce new evidence in this challenging area.

ACKNOWLEDGEMENTS: The authors acknowledge the cooperation all of the nursing staff and Nursing Unit Managers for the study wards at the Foothills Medical Centre. The authors also thank Drs S Majumdar and Dr F McAlister of the University of Alberta for their contributions to the patient allocation design, and Dr M Mah of the University of Calgary for helpful contributions to the overall design of the study. The authors are indebted to the Calgary Health Region Administration for their support throughout all phases of the study. Financial support for the conduct of this study was provided by the Canadian Institutes of Health Research and the Alberta Heritage Foundation for Medical Research, along with contributions-in-kind from the former Calgary Health Region in the Partnerships for Health System Improvement Program. William Ghali is funded by an Alberta Innovates - Health Solutions Senior Health Scholar Award.

DISCLOSURES: None of the authors have any conflicts of interest involving the work under consideration for publication in this article.

\section{REFERENCES}

1. CDC and the Healthcare Infection Control Practices Advisory Committee (HICPAC). Guidelines for environmental infection control in health-care facilities: Recommendations of CDC and the healthcare infection control practices Committee (HICPAC). MMWR Morb Mortal Wkly Rep 2003;52(RR-10):1-42.

2. McDonald LC, Walker M, Carson L, et al. Outbreak of Acinetobacter spp bloodstream infections in a nursery associated with contaminated aerosols and air conditioners. Ped Infect Dis J 1998; 17:716-22.

3. Kumari DN, Haji TC, Keer V, et al. Ventilation grilles as a potential source of methicillin-resistant Staphylococcus aureus causing an outbreak in an orthopedic ward at a district general hospital. J Hosp Infect 1998;29:127-33.

4. Opal SM, Asp AA, Cannady BP Jr, et al. Efficacy of infection control measures during a hospital-acquired outbreak of disseminated Aspergillosis associated with hospital construction. J Infect Dis 1986;153:634-7.

5. Loo VG, Bertrand C, Dixon C, et al. Control of constructionassociated hospital-acquired aspergillosis on an antiquated hematology unit. Infect Contr Hosp Epidemiol 1986;17:360-4.

6. Menzies D, Fanning A, Yuan L, Fitzgerald M. Hospital ventilation and risk for tuberculosis infection in Canadian healthcare workers. Ann Int Med 2000;133:779-89.

7. Scott DR. Centers for Disease Control and Prevention. The direct medical costs of healthcare-associated infections in US hospitals and the benefits of prevention. March 2009. <www.cdc.gov/HAI/ pdfs/hai/Scott_CostPaper.pdf> (Accessed August 30, 2012).

8. Ulrich R, Quan X, Zimring C, Joseph A, Choudhary R. The role of the physical environment in the hospital of the 21st century: A once-in-a-life opportunity. The Center for Health Design. Concord, California < www.healthdesign.org/chd/research/role-
With respect to financial disclosures, John Conly has received honoraria from the Canadian Agency for Drugs and Technologies in Health for work as an expert reviewer and clinical expert, respectively, for projects on the role of rapid polymerase chain reaction testing for MRSA in hospitalized patients, and the use of vancomycin or metronidazole for treatment of $\mathrm{C}$ difficile colitis within the past three years. He has also received speaker's honoraria related to new antibacterial agents from JanssenOrtho and Pfizer during the past three years. He has received financial support for MRSA research activities from the Alberta Heritage Foundation for Medical Research, the Canadian Institutes for Health Research and Pfizer. John Conly and William Ghali, as principal and coprincipal investigators, respectively, had full access to all the data in the study and take responsibility for the integrity of the data and the accuracy of the data analysis. All authors made substantial contributions to data acquisition, data analysis, interpretation of results, writing of the manuscript and/or revision of the final draft. Detailed author contributions are as follows: J Ellison was responsible for day-to-day data collection, data acquisition, data cleaning, partial data analysis and interpretation, and manuscript writing and revision; D Southern was responsible for data acquisition, data cleaning, detailed data analysis and interpretation, and manuscript writing and revision; P Faris, J Wallace, B Henderson and D Holton were responsible for components of the grant proposal writing, study planning, data interpretation, manuscript writing and general supervision for each of their respective components of the study. J Conly and W Ghali were responsible for the original project conception and refinement, grant proposal writing, data collating, interpretation, manuscript writing and overall general supervision of the study. The findings from this study were presented, in part, in abstract form at the Infectious Diseases Society of America Annual Meeting (Abstract 475), San Diego, California, October 17 to 21, 2012. Trial Registration: ClinicalTrials.gov, National Institutes of Health Registration number: NCT00563186 URL: http://clinicaltrials.gov/ct2/ show/NCT00563186

physical-environment-hospital-21st-century?page $=$ show $>$ (Accessed August 30, 2012).

9. Lye T, Conly J, Henderson E, et al. The impact of physical plant design and engineering controls to reduce the burden of Hospitalacquired infections. Abstract. Society for Healthcare Epidemiology of America, Annual Scientific Meeting, San Diego, March 19 to 22, 2009.

10. Cebul RD. Randomized controlled trials using the Metro Firm System. Med Care 1991;29:(7 Suppl):JS9-S18.

11. Goldberg $\mathrm{H}, \mathrm{McG}$ ough $\mathrm{H}$. Ethics of ongoing randomization trials investigations among intimates. Med Care 1991;29(7 Supp):JS41-48.

12. The Canadian Nosocomial Infection Surveillance Program. <www.phac-aspc.gc.ca/nois-sinp/projects/cdad-eng.php> (Accessed August 30, 2012).

13. Dettenkofer M, Seegers S, Antes G, Motschall E, Schumacher M, Daschner FD. Does the architecture of hospital facilities influence hospital-acquired infection rates? A systematic review. Infect Control Hosp Epidemiol 2004;25:21-5.

14. van de Glind I, de Roode S, Goossensen A. Do patients in hospitals benefit from single rooms? A literature review. Health Policy 2007;84:153-61.

15. Teltsch DY, Hanley J, Loo V, Goldberg P, Gursahaney A, Buckeridge DL. Infection acquisition following intensive care unit room privatization. Arch Intern Med 2011;171:32-8.

16. Levin PD, Golovanevski M, Moses AE, Sprung CL, Benenson S. Improved ICU design reduces acquisition of antibiotic-resistant bacteria: A quasi-experimental observational study. Crit Care 2011;15:R211.

17. Cepeda JA, Whitehouse T, Cooper B, et al. Isolation of patients in single rooms or cohorts to reduce spread of MRSA in intensive-care units: Prospective two-centre study. Lancet 2005;365:295-304. 


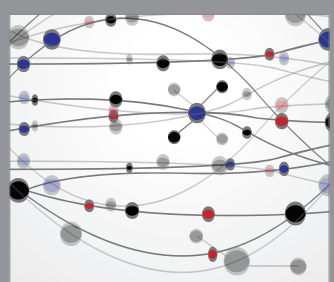

The Scientific World Journal
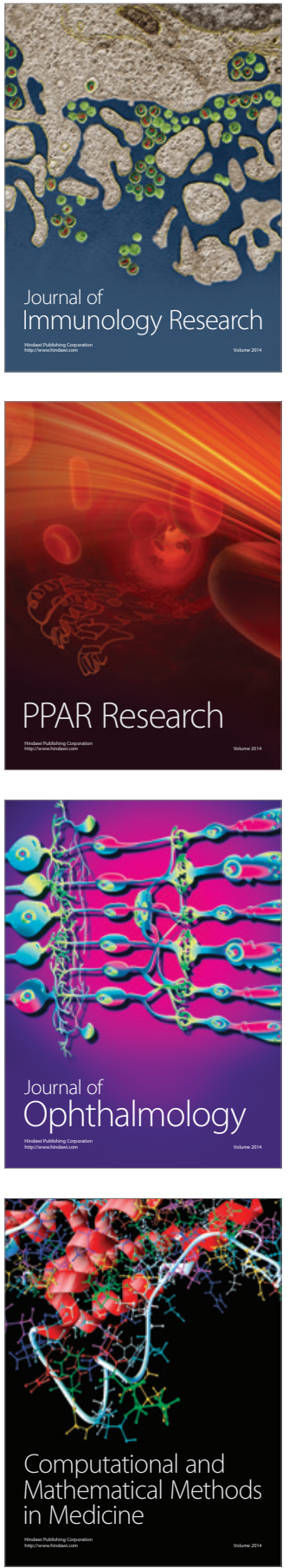

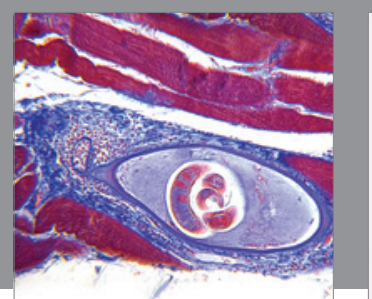

Gastroenterology Research and Practice

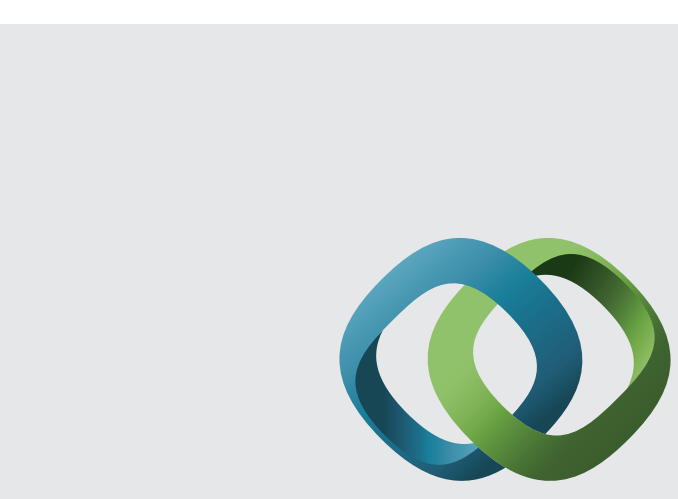

\section{Hindawi}

Submit your manuscripts at

http://www.hindawi.com
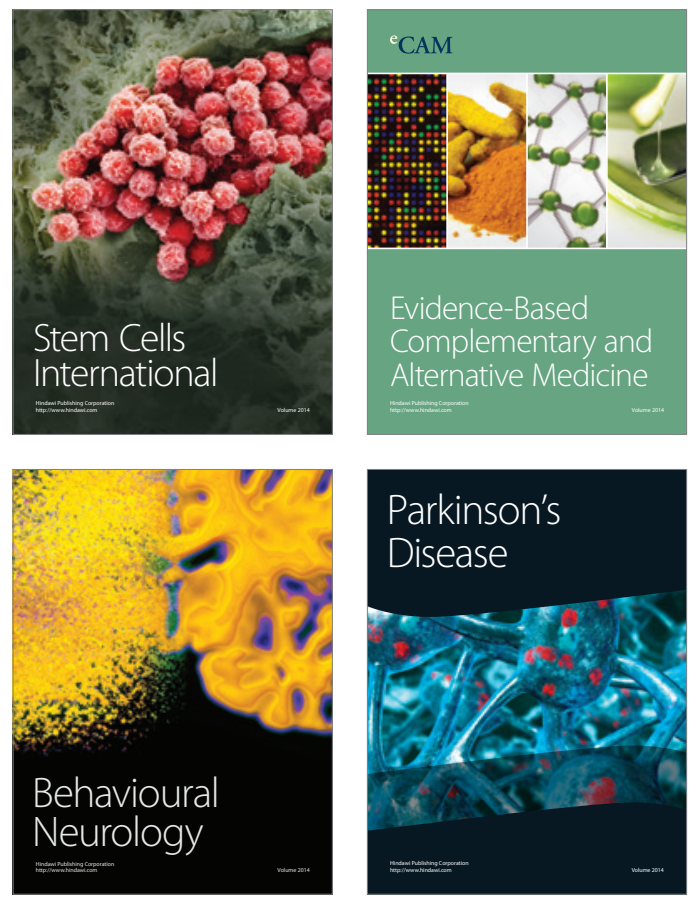
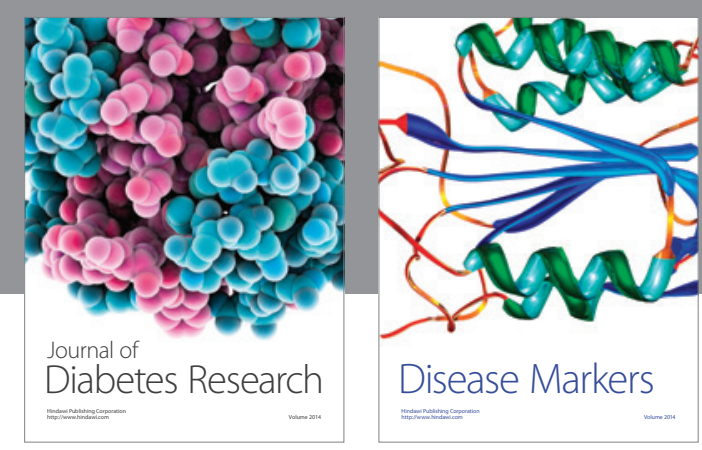

Disease Markers
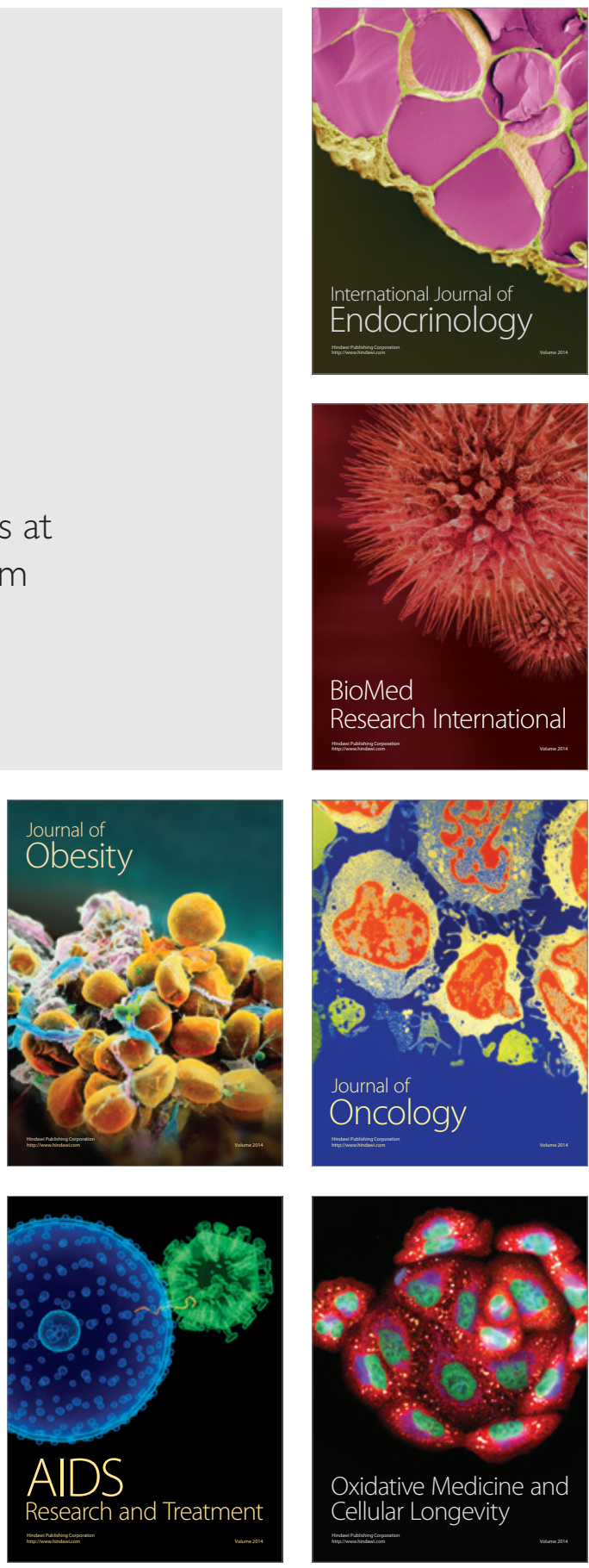